\title{
Experience with use of gonadotropin releasing hormone agonists in patients with cancer for fertility preservation
}

\author{
Al-Jaroudi $\mathrm{D}^{*}$, Abdulla $\mathrm{R}^{1}$, Bashir $\mathrm{M}^{2}$ and Al-Badr $\mathrm{A}^{2}$ \\ ${ }^{1}$ Reproductive Endocrine and Infertility Medicine Department, Women's Specialized Hospital, King Fahad Medical City, Riyadh, Saudi Arabia \\ ${ }^{2}$ Research Center, King Fahad Medical City, Riyadh, Saudi Arabia
}

\begin{abstract}
Background: Patients with cancer must be aware of preventive measures that can be undertaken to preserve their fertility before embarking on gonadotoxic therapy. Different theories have been published on the efficacy and the mechanism of action of gonadotropin releasing hormone agonists (GnRHa) in preventing ovarian failure. We hereof report our experience with the GnRHa, leuprolide $\left(\right.$ Lupron $\left.^{\circledR}\right)$, used before chemotherapy to preserve ovarian function concerning resumption of menses and fertility.

Objective: To determine whether GnRHa could prevent the early onset of ovarian insufficiency and resume menses in patients with cancer who received chemotherapy.

Methods: This is a retrospective case series that included all pre-menopausal women, who attended a tertiary referral center, between December 2010 and December 2015. Patients who are diagnosed with cancer had been referred from the oncology department before receiving chemotherapy. Women were given leuprolide (luteinizing hormone releasing hormone agonist) monthly, which was started before or at first chemotherapy cycle and continued every month until the last cycle of chemotherapy. The GnRHa was started 3-20 days before treatment. The main clinical endpoint was the recovery of menstruation after chemotherapy. The other end point was the rate of successful conception post chemotherapy.

Results: Twelve patients were included in the study. Median age was 25.5 years (range 16-48); eleven patients (92\%) were less than the age of 40. Most of the patients were single, nine $(75 \%)$, and only three $(25 \%)$ were married; two patients had infertility problems (16.7\%). Patients received different regimens of chemotherapy, according to their type of cancer. Resumption of menstrual activity after chemotherapy was observed in 10 out of 12 patients (83.3\%), and all were less than 40 years. The median time to recovery of menses was 2 to 3 months after cessation of chemotherapy. The paired t-test has shown that there is a statistical significant difference between of FSH serum level before and after administering Leuprolide $(\mathrm{P}=0.025)$. On the other hand, there is moderate significant correlation $(\mathrm{r}=0.285)$ between FSH serum level before and after administering Leuprolide.
\end{abstract}

Conclusion: Current case series, suggests that use of GnRHa given with chemotherapy for cancer patients is successful in preventing chemotherapy-induced amenorrhea. Larger studies are needed to affirm this finding.

\section{Introduction}

Benjamin Franklin's axiom “an ounce of prevention is worth a pound of cure" applies well to our management plan as physicians when treating cancer patients $[1,2]$. Patients with cancer must be informed about the available preventive measures that can be undertaken to preserve their fertility before embarking on gonadotoxic therapy. Unfortunately, the incidence of cancer in patients in their reproductive age is increasing; nevertheless, the long-term survival after treatment is also increasing [2]. This has given lots of hope to the young patients regarding survival and possible future fertility. The improvement in survival after chemotherapy came at the expense of ovarian function, thus increasing the risk of ovarian insufficiency and infertility.

Ovarian transposition, cryopreservation of oocytes, ovarian tissue, and embryos, along with the administration of gonadotropinreleasing hormone agonists $(\mathrm{GnRHa})$ are various fertility preservation options that can be offered to cancer patients [3]. Several societies have recommended discussing the various fertility preservation options with patients before they undergo chemotherapy for cancer treatment [3-5]. Several reports have been published on the effectiveness of a GnRHa during chemotherapy to preserve ovarian function in women undergoing chemotherapy [6]. Different theories have been published on the efficacy and the mechanism of action of GnRHa in preventing ovarian failure [7]. The decrease in ovarian perfusion, the suppression of pituitary Follicular Stimulation Hormone (FSH), and the activation of GnRH receptors are some of the theories that have been published [7]. Studies on both humans and animals have shown that ovarian suppression by GnRHa may preserve ovarian function [7].

We hereof report our experience with the GnRHa, leuprolide $\left(\right.$ Lupron $\left.^{\circ}\right)$, used with chemotherapy to preserve ovarian function and maintain fertility regarding the resumption of menses.

\section{Methods}

A retrospective cohort study that included women who attended

Correspondence to: Dania H. Al-Jaroudi, Assistant Professor, King Saud bin Abdulaziz University for Health Sciences, Reproductive Endocrinology and Infertility Medicine Department, King Fahad Medical City, Saudi Arabia; Tel: +966 1288 9999, Ext. 21100; Email: daljaroudi@kfmc.med.sa

Key words: fertility preservation, amenorrhea, GnRH agonists, LHRH agonists, cancer

Received: February 02, 2017; Accepted: February 21, 2017; Published: February 23, 2017 
Women's Specialized Hospital, Reproductive endocrinology clinic, King Fahad Medical City, Riyadh, Saudi Arabia, between December 2010 and December 2015. Patients diagnosed with cancer had been referred from the oncology department before receiving chemotherapy. Pre-menopausal women were given leuprolide (luteinizing hormone releasing hormone agonist) $3.75 \mathrm{mg}$ intramuscularly monthly, which was started before or at first chemotherapy cycle and continued every month until the last cycle of chemotherapy, except for one patient who had received $1.88 \mathrm{mg}$. The main clinical endpoint was the recovery of menstruation after chemotherapy. The other end point was the rate of successful conception post chemotherapy. Institutional Review Board approved the study before data collection. All categorical variables marital status, infertility, and menstrual history will be presented as numbers and percentages. Continuous variables age, BMI, TSH, F4, and FSH will be expressed as median, range and Mean \pm S.D. Spearman rank correlation coefficient test will be applied to determine the significant association between FSH before and after administering Leuprolide, and also Wilcoxon signed rank test will be used to find out mean rank differences. P - value of less than 0.05 is considered as statistically significant. All data was entered and analyzed through statistical package SPSS version 22.

\section{Results}

Twelve patients are included in the study. Median age was 25.5 years (range 16-48); eleven patients (92\%) were lower than the age of 40. Most of the patients were single, nine (75\%), and only three (25\%) were married; two patients had infertility problems (16.7\%) (Table 1). Patients are diagnosed with various types of cancer (Table 2).

Patients received different regimens of chemotherapy, according to their type of cancer (Table 1). Resumption of menstrual activity after chemotherapy achieved in 10 out of 12 patients $(83.3 \%)$, and all were less than 40 years. The median time to recovery of menses was 2 to 3 months after cessation of chemotherapy. The paired t-test has shown that there is a statistical significant difference between of FSH serum level before and after administering Leuprolide $(\mathrm{P}=0.025)$. On the other hand, there is significant correlation $(r=0.285)$ between FSH serum level before and after administering Leuprolide (Table 3). Of the three patients who attempted pregnancy, none got pregnant.

\section{Discussion}

There is a lack of definite benefit concerning fertility preservation when using GnRHa before chemotherapy [8]. This is because most of the studies have looked at the resumption of menses and the long-term fertility outcomes such as pregnancy [8]. Resumption of menstrual activity after chemotherapy was observed in $83.3 \%$ of our patients who had received leuprolide before chemotherapy. Those women were young, all younger than 40 apart from one patient, and thus avoiding Premature Ovarian Failure (POF). This is of great importance in this subset of women to preserve future fertility. A randomized controlled trial in 2009, has shown that GnRHa before chemotherapy had beneficial effects concerning the resumption of menses [9]. This was in concordance with our study that has shown that there is a beneficial effect regarding the resumption of menses in cancer patients who received GnRHa (Leuprolide $3.75 \mathrm{mg} \mathrm{IM}$ ) before chemotherapy. There was no report of protection of fertility in those studies, and this was similar to our report as well.

Gerber et al. [10] did a prospective randomized open label controlled multicenter study (ZORO trial). They included 60 patients younger than 46 years of age with hormone insensitive breast cancer
Table 1. Basic and clinical characteristics of Patients $(n=12)$.

\begin{tabular}{|c|c|c|}
\hline Characteristics & Categories & n (\%) \\
\hline \multirow[t]{2}{*}{ Marital Status } & Single & $9(75.0 \%)$ \\
\hline & Married & $3(25.0 \%)$ \\
\hline \multirow[t]{2}{*}{ Infertility } & No & $11(91.7 \%)$ \\
\hline & Yes & $1(8.3 \%)$ \\
\hline \multirow[t]{2}{*}{ Cause of Infertility } & None & $11(91.7 \%)$ \\
\hline & anovulation & $1(8.3 \%)$ \\
\hline \multirow[t]{2}{*}{ Menstrual History } & Regular & $11(91.7 \%)$ \\
\hline & Irregular & $1(8.3 \%)$ \\
\hline \multirow[t]{10}{*}{ Diagnosis of Cancer } & Hodgkin lymphoma & $2(16.7 \%)$ \\
\hline & Non - Hodgkin lymphoma & $1(8.3 \%)$ \\
\hline & Acute lymphocytic leukaemia & $1(8.3 \%)$ \\
\hline & Mucinous cyst adenocarcioma & $1(8.3 \%)$ \\
\hline & Ovarian teratoma (immature) & $1(8.3 \%)$ \\
\hline & Breast cancer & $1(8.3 \%)$ \\
\hline & Yolk sac tumour & $2(16.7 \%)$ \\
\hline & Granulosa cell tumour & $1(8.3 \%)$ \\
\hline & Mixed Germ Cell Tumour & $1(8.3 \%)$ \\
\hline & Ovarian Dysgerminoma & $1(8.3 \%)$ \\
\hline \multirow[t]{2}{*}{ USS (ovaries) } & Ovaries Normal & $7(58.3 \%)$ \\
\hline & Unilateral Ovarian Cyst $<3 \mathrm{~cm}$ & $5(41.7 \%)$ \\
\hline \multirow[t]{2}{*}{ Drug History } & Yes & $1(8.3 \%)$ \\
\hline & No & $11(91.7 \%)$ \\
\hline \multirow[t]{2}{*}{ Leuprolide dose } & $1.88 \mathrm{mg}$ & $1(8.3 \%)$ \\
\hline & $3.75 \mathrm{mg}$ & $11(91.7 \%)$ \\
\hline \multirow[t]{4}{*}{ Leuprolide total doses } & 1 Doses & $1(8.3 \%)$ \\
\hline & 3 Doses & $4(33.3 \%)$ \\
\hline & 4 Doses & $4(33.3 \%)$ \\
\hline & 6 Doses & $3(25.0 \%)$ \\
\hline \multirow[t]{4}{*}{ Days before chemotherapy } & 10 days & $2(16.7 \%)$ \\
\hline & 20 days & $2(16.7 \%)$ \\
\hline & 3 days & $1(8.3 \%)$ \\
\hline & 7 days & $7(58.3 \%)$ \\
\hline \multirow[t]{10}{*}{ Cycle After Leuprolide } & No Cycle & $4(33.3 \%)$ \\
\hline & 1 Cycle & $1(8.3 \%)$ \\
\hline & 2 Cycle & $2(16.7 \%)$ \\
\hline & $3-6$ Cycles & $5(41.7 \%)$ \\
\hline & FEC & $1(8.3 \%)$ \\
\hline & ABVD & $2(16.7 \%)$ \\
\hline & BEP & $6(50.0 \%)$ \\
\hline & RCHOP & $1(8.3 \%)$ \\
\hline & CARBO/TAXEL & $1(8.3 \%)$ \\
\hline & COG & $1(8.3 \%)$ \\
\hline \multirow[t]{2}{*}{ Fertility Treatment } & Yes & $1(8.3 \%)$ \\
\hline & No & $11(91.7 \%)$ \\
\hline
\end{tabular}

Table 2. Descriptive statistics, Age, BMI, FT4 and FSH.

\begin{tabular}{|l|l|l|l|l|l|}
\hline & Minimum & Maximum & Range & Median & Mean \pm S.D \\
\hline Age (years) & 16.00 & 48.00 & 32.00 & 25.50 & $25.38 \pm 7.85$ \\
\hline BMI $\left(\mathrm{kg} / \mathrm{m}^{2}\right)$ & 17.10 & 37.50 & 20.40 & 21.00 & $23.54 \pm 6.08$ \\
\hline Duration $(\mathrm{months})$ & 4.00 & 7.00 & 3.00 & 1.50 & $1.38 \pm 0.63$ \\
\hline E2 (Pmol/L) & 127.00 & 401.00 & 274.00 & 248.00 & $256 \pm 33.06$ \\
\hline PROLACTIN (mlU/L) & 178.00 & 485.00 & 307.00 & 460.00 & $374.33 \pm 170.48$ \\
\hline FT4 (Pmol/L) & 13.30 & 20.60 & 7.30 & 15.10 & $16.01 \pm 2.77$ \\
\hline TSH (mIU/L) & 0.32 & 4.04 & 3.72 & 2.56 & $2.33 \pm 1.27$ \\
\hline FSH (IU/L) & 7.80 & 23.60 & 15.80 & 8.30 & $13.23 \pm 8.98$ \\
\hline LH (IU/L) & 5.70 & 14.00 & 8.30 & 11.10 & $10.26 \pm 4.21$ \\
\hline $\begin{array}{l}\text { FSH after Leuprolide } \\
\text { (IU/L) }\end{array}$ & 7.70 & 40.20 & 32.50 & 27.25 & $25.6 \pm 16.15$ \\
\hline
\end{tabular}

who received goserlin $3.6 \mathrm{mg}$ subcutaneously every four weeks, two weeks before chemotherapy cycle until completion of chemotherapy. 
Table 3. FSH status before and after intervention of Leuprolide.

\begin{tabular}{|l|c|c|c|c|}
\hline & Minimum & Maximum & Mean Rank & Spearman Rank Correlation \\
\cline { 1 - 2 } FS before Leuprolide & 7.80 & 23.60 & 1.50 & 0.285 \\
\hline FSH after Leuprolide & 7.70 & 40.20 & 4.00 & $* 0.025$ \\
\hline
\end{tabular}

They concluded that there is no significant difference in the rate of amenorrhea among breast cancer patients who received GnRHa before chemotherapy and those who did not [10]. The results had some limitations, which are the short follow-up of patients, up to 6 months only. Additionally, patients were of younger age group, and the lower number of chemotherapy cycles administered. However, when the authors of the ZORO trial extended their follow up period to 24 months, they still did not report any long-term benefit after GnRHa on pregnancy [10]. Gerber et al. [10] have reported that amenorrhea rate was the same in premenopausal patients with breast cancer receiving goserelin simultaneously with modern neoadjuvant chemotherapy.

This was similar to the systematic review and meta-analysis done by Vitek et al, who looked at whether concurrent use of GnRHa with chemotherapy preserves ovarian function in women with breast cancer, in whichtamoxifen was not used. They concluded that concurrent GnRHa use with chemotherapy does not preserve ovarian function in women with breast cancer [11].

Del Mastro et al. [12] performed a systematic review and metaanalysis of randomized trials, evaluating the efficacy of GnRHa, given before and during chemotherapy, in the prevention of POF in cancer patients. They found that out of 765 analyzed patients, 225 had POF [12]. They concluded that the risk of chemotherapy-induced POF in young cancer patients after GnRHa is significantly reduced [12]. Another meta-analysis by Shen et al. in 2015 that looked at the efficacy of GnRHa administered alongside chemotherapy to prevent chemotherapy-induced ovarian damage in premenopausal women with breast cancer [13]. They concluded that the GnRHa has helped in the resumption of menses but did not show a protective effect regarding fertility [13]. The ASCO do not recommend the use of GnRHa as a fertility preservation method due to lack of sufficient evidence. However, they strongly encourage all health care providers, to discuss the risk of infertility and fertility preservation options with patients with cancer anticipating treatment [3].

The limitation of our study is the limited number of patients, plus the lack of control group. Regrettably, the number of referrals from the oncology department was limited. Additionally, the primary outcome in this study was the resumption of menses at 12 months' follow-up, which does not address the group of women who had POF, and those who had become pregnant and delivered, or ability to conceive.

\section{Conclusion}

Leuprolide administration before chemotherapy may prevent amenorrhea in cancer patients. However, with the presence of contradictory reports and the conflicting evidence of the beneficial effects of GnRHa concerning fertility preservation and with the lack of well-designed randomized controlled trial, it is reasonable for physicians to present to the patients the options of fertility preservation available, including the GnRHa before embarking on chemotherapy.

\section{References}

1. Fire Department: The Electric Ben Franklin, USHISTORY.ORG, http://www.ushistory org/

2. franklin/philadelphia/fire.htms (last visited May 18, 2011).

3. Blumenfeld Z, Katz G, Evron A (2014) 'An ounce of prevention is worth a pound of cure': the case for and against GnRH-agonist for fertility preservation. Ann Oncol 25: 1719-1728. [Crossref]

4. Loren AW, Mangu PB, Beck LN, Brennan L, Magdalinski AJ, et al. (2013) Fertility preservation for patients with cancer: American Society of Clinical Oncology clinical practice guideline update. J Clin Oncol 31:2500. [Crossref]

5. Practice Committee of American Society for Reproductive Medicine (2013) Fertility preservation in patients undergoing gonadotoxic therapy or gonadectomy: a committee opinion. Fertil Steril 100: 1214-1223. [Crossref]

6. The Ethics Committee of the American Society for Reproductive Medicine (2013) Fertility preservation and reproduction in patients facing gonadotoxic therapies: a committee opinion. Fertil Steril 100:1224. [Crossref]

7. Clowse ME, Behera MA, Anders CK, Copland S, Coffman CJ, et al. (2009) Ovarian preservation by $\mathrm{GnRH}$ agonists during chemotherapy: a meta-analysis. $J$ Womens Health (Larchmt) 18: 311-319. [Crossref]

8. Lambertini M, Ceppi M, Poggio F, Peccatori FA, Azim H Jr, et al. (2015) Ovarian suppression using luteinizing hormone-releasing hormone agonists during chemotherapy to preserve ovarian function and fertility of breast cancer patients: a meta-analysis of randomized studies Ann Oncol 26: 2408-19. [Crossref]

9. Bedoschi G, Turan V, Oktay K (2013) Utility of GnRH-agonists for Fertility Preservation in Women with Operable Breast Cancer: Is It Protective? Curr Breast Cancer Rep 5: 302-308. [Crossref]

10. Badawy A, Elnashar A, El-Ashry M, Shahat M (2009) Gonadotropin-releasing hormone agonists for prevention of chemotherapy-induced ovarian damage: prospective randomized study. Fertil Steril 91:694-97. [Crossref]

11. Gerber B, von Minckwitz G, Stehle H, Reimer T, Felberbaum R, et al. (2011) German Breast Group Investigators. Effect of luteinizing hormone-releasing hormone agonist on ovarian function after modern adjuvant breast cancer chemotherapy: the GBG 37 ZORO study. J Clin Oncol 29:2334-41. [Crossref]

12. Vitek WS, Shayne M, Hoeger K, Han Y, Messing S, et al (2014) Gonadotropinreleasing hormone agonists for the preservation of ovarian function among women with breast cancer who did not use tamoxifen after chemotherapy: a systematic review and meta-analysis. Fertil Steril 102:808-15. [Crossref]

13. Del Mastro L, Ceppi M, Poggio F, Bighin C, Peccatori F, et al. (2014) Gonadotropinreleasing hormone analogues for the prevention of chemotherapy-induced premature ovarian failure in cancer women: systematic review and meta-analysis of randomized trials. Cancer Treat Rev 40:675-83. [Crossref]

14. Shen YW, Zhang XM, Lv M, Chen L, Qin TJ, et al. (2015) Utility of gonadotropinreleasing hormone agonists for prevention of chemotherapy-induced ovarian damage in premenopausal women with breast cancer: a systematic review and meta-analysis. Onco Targets Ther 13: 3349-59. [Crossref]

Copyright: (C2017 Al-Jaroudi D. This is an open-access article distributed under the terms of the Creative Commons Attribution License, which permits unrestricted use, distribution, and reproduction in any medium, provided the original author and source are credited. 